\title{
ANALYSIS OF GROWTH INDEXES IN CHILDREN ATTENDING NURSERIES
}

\author{
Gergana Markova ${ }^{1}$, Gergana Petrova ${ }^{2}$ \\ 1) Department of Surgical nursing care, Faculty of Health Care, Medical \\ University - Pleven, Bulgaria. \\ 2) Department of Nursing, Faculty of Public Health, Medical University of \\ Plovdiv, Bulgaria.
}

\section{SUMMARY:}

Purpose: By means of comparative analysis of the growth indexes (height and weight) in children in their early childhood, attending nurseries, an assessment to be made of the health care taken of them.

Materials and Methods: Observation - Conduct of a disclosed observation in a natural environment of newly admitted children to the located on the territory of Pleven Municipality, Bulgaria. Object of observation are the indexes evidencing the physical development of the children. By tracing the changes in the indexes, it is possible to make an assessment in dynamics with regard to the care taken of the children during their stay in the nurseries. Subject of observation are the children attending the nurseries and the groups in the unified children's establishments in the municipality of Pleven, Bulgaria. Ninety children have been observed, with the informed written consent given by the parents.

Results: Comparing the results with the criteria of WHO it can be said that upon commencement of the observation, the height of all children depending on their age and sex, is normal. There are certain deviations above the norm with regard to their weight. With the increase in the children's age, the curve of the height is displaced to the right by around $5 \mathrm{~cm}$. The average annual growth is $5.3 \mathrm{~cm}$, with a rate of $8 \mathrm{~cm}$ indicated by WHO.

Conclusion: The results obtained in terms of height and weight completely correspond to the norms for physical development for the relevant age, proposed by the experts of the World Health Organization.

Keywords: Health care, children, nurseries

\section{INTRODUCTION:}

In Bulgaria, a large number of children in their early childhood are raised and brought up in nurseries. Pursuant to Art. 2 (1) of Ordinance No: 26 of 18 November 2008 on the structure and activity of nurseries and children's kitchens and the health requirements towards them, "nurseries are organizationally differentiated structures where medical, and other specialists bring up, raise and educate children from the age of 3 months to 3 years" [1]. In our country, those establishments are part of the healthcare system, and their main task is strengthening of children's health.

One of the main dimensions of health is physical. It means the correct functioning of the organism and its systems and bodies. Physical health is decisive for overall well-being. It is the most visible dimension of health $[2,3,4]$. Physical development is one of the components of physical health and may be used as an index of health assessment. The concept of physical development reflects the combination of morphological, functional and mental properties, characterizing the level and dynamics of growth of the organism and its abilities to adapt to the changing conditions of life. While studying and assessing physical development, three groups of signs are used:

- anthropometric: height, weight, chest measurement, etc.

- physiometric: vital capacity, muscle strength, reactivity and precision of movements;

- somatoscopic: figure, muscle development, a form of thorax and legs, development of genitals in men, secondary sex characteristics, puberty.

The new standards of WHO prove that the differences in the physical development of children up to the age of 5 are more influenced by the food, environment and healthcare than the genetic component and ethnical belonging [5]. This provides an opportunity, through a study and assessment of the physical development of children, to evaluate and analyze the care taken of them.

\section{AIM:}

By means of comparative analysis of the growth indexes (height and weight) in children in their early childhood, attending nurseries, an assessment to be made of the health care taken of them.

\section{MATERIALS AND METHODS:}

Observation - Conduct of a disclosed observation in a natural environment of newly admitted children to the nurseries located on the territory of Pleven Municipality. Dropping of the study is possible upon discharge from the irrespective of the reason thereof, or at the explicit wish of the parents. Object of observation are the indexes evidencing the physical development of the chil- 
dren. By tracing the changes in the indexes, it is possible to make an assessment in dynamics with regard to the care taken of the children during their stay in the nurseries. Subject of observation are the children attending the s and the groups in the unified children's establishments in the municipality of Pleven. Ninety children have been observed form September 2015 to august 2017, with the informed written consent, given by the parents.

Statistical methods: The data on the study have been processed using software statistical packages STATGRAPHICS; SPSS 19 and EXCEL for Windows.

The results are described in tables, charts and numeral indexes in terms of structure, frequency, mean values, correlation coefficients, etc.

Upon analysis of the results, the following parametric tests have been applied for verification of hypotheses in normal and close to normal distribution of the cases: $t$ - test, ANOVA with post hoc tests Tukey, Scheffe, Bonferroni, Newman-Keuls, Duncan and the non-parametric tests in case distribution other than normal: Pearson' $\chi^{2}$ - test, Mann-Whitney, Kruscal-Wallis H-test.

Regression models have been used for modeling and prognostication of correlation dependencies.

The significance of the results, conclusions and inferences has been determined at $\mathrm{p}<0,05$.

\section{RESULTS:}

Results and discussion: On the basis of the results of the study, a structure was made (upon launching of the observation), of the persons included in the observation by sex and age. The boys prevail $(54,44 \% ; n=90)$. The differences by "sex" are minimum and most probably are due to the tendency of giving birth to more boys [6], as in this case. In 2012 in Pleven Municipality (the year in which 64 of the observed children were born $-51.08 \%$ of all newborns were boys and in 2013 - (the year of birth of 26 of the children taking part in the observation, - the relative share of the male newborns is 50, 95\% [7]. With respect to age, the subjects of the study form 2 age groups: children between 1, $6-2$ years old and children from 2 , 1 to 2.6 years old. The bigger relative share $-71,11 \%$ (64) belongs to the children from 2.1 to 2.6 years of age.

The children with height between $87-90 \mathrm{~cm}$ prevail - 41,11\% ( $\mathrm{n}=90)$, and 5,6\% (5) are $96 \mathrm{~cm}$ tall (Table 1). Logically, the children from the higher age group (2.1 2.6 years) are taller. A significant correlation dependency $(\mathrm{p}=0,0009 ; \mathrm{r}=0,51)$. The boys are higher $(\mathrm{p}=0,0008$; $\mathrm{r}=0,51$ ), with the exception of the 5 children who are 96 $\mathrm{cm}$ tall and are female (Table 2). The average height of the studied individuals is $88.9 \mathrm{~cm}$. With respect to the weight, $44,4 \%(n=90)$ of the children have body mass between $12-14 \mathrm{~kg}$. The lowest relative share $-6.7 \%$ (6) belongs to the persons with body mass $16-18 \mathrm{~kg}$, provided that five of the children weigh $16.1 \mathrm{~kg}-16.5 \mathrm{~kg}$ and one of them $18 \mathrm{~kg}$. The average weight of the observed population is $13.14 \mathrm{~kg}$. The age $(\mathrm{p}<0,05 ; \mathrm{r}=0,6)$, height $(\mathrm{p}=0,02 ; \mathrm{r}=0,9)$ and $\operatorname{sex}(\mathrm{p}<0,05 ; \mathrm{r}=0,6)$ of the children have a significant influence on their body mass (Table 1 and Table 2).

Table 1. Physical development of the studied individuals depending on their age

\begin{tabular}{|c|c|c|c|c|c|c|c|c|}
\hline \multirow{2}{*}{ Indicators } & \multicolumn{9}{|c|}{ Age } \\
\cline { 2 - 9 } & \multicolumn{3}{|c|}{$1,6-2$ years } & \multicolumn{5}{c|}{$2,1-2,6$ years } \\
\hline Height & $83-86 \mathrm{~cm}$ & $87-90 \mathrm{~cm}$ & $91-94 \mathrm{~cm}$ & $96 \mathrm{~cm}$ & $83-86 \mathrm{~cm}$ & $87-90 \mathrm{~cm}$ & $91-94 \mathrm{~cm}$ & $96 \mathrm{~cm}$ \\
\hline Relative share & $15,55 \%$ & $13,33 \%$ & $0 \%$ & $0 \%$ & $11,11 \%$ & $27,77 \%$ & $26,66 \%$ & $5,56 \%$ \\
\hline Weight & $10-12 \mathrm{~kg}$ & $12,1-14 \mathrm{~kg}$ & $14,1-16 \mathrm{~kg}$ & $\mathbf{1 6 , 1 - 1 8} \mathrm{kg}$ & $10-12 \mathrm{~kg}$ & $12,1-14 \mathrm{~kg}$ & $14,1-16 \mathrm{~kg}$ & $16,1-18 \mathrm{~kg}$ \\
\hline Relative share & $14,44 \%$ & $11,11 \%$ & $2,22 \%$ & $\mathbf{1 , 1 1 \%}$ & $12,22 \%$ & $33,33 \%$ & $20 \%$ & $5,55 \%$ \\
\hline
\end{tabular}

Table 2. Physical development of the studied individuals depending on their sex

\begin{tabular}{|c|c|c|c|c|c|c|c|c|}
\hline \multirow{2}{*}{ Indicators } & \multicolumn{9}{|c|}{ Sex } \\
\cline { 2 - 9 } & \multicolumn{3}{|c|}{ Male } & \multicolumn{4}{c|}{ Female } \\
\hline Height & $83-86 \mathrm{~cm}$ & $87-90 \mathrm{~cm}$ & $91-94 \mathrm{~cm}$ & $96 \mathrm{~cm}$ & $83-86 \mathrm{~cm}$ & $87-90 \mathrm{~cm}$ & $91-94 \mathrm{~cm}$ & $96 \mathrm{~cm}$ \\
\hline Relative share & $6,7 \%$ & $33,3 \%$ & $14,4 \%$ & $0 \%$ & $20,0 \%$ & $7,8 \%$ & $12,2 \%$ & $5,6 \%$ \\
\hline Weight & $10-12 \mathrm{~kg}$ & $12,1-14 \mathrm{~kg}$ & $14,1-16 \mathrm{~kg}$ & $16,1-18 \mathrm{~kg}$ & $10-12 \mathrm{~kg}$ & $12,1-14 \mathrm{~kg}$ & $14,1-16 \mathrm{~kg}$ & $16,1-18 \mathrm{~kg}$ \\
\hline Relative share & $7,77 \%$ & $32,22 \%$ & $12,22 \%$ & $2,22 \%$ & $18,88 \%$ & $12,22 \%$ & $10,0 \%$ & $4,44 \%$ \\
\hline
\end{tabular}

With the increase in the children's age, the curve of the height is displaced to the right by around $5 \mathrm{~cm}$. The average annual growth is $5.3 \mathrm{~cm}$, with a rate of $8 \mathrm{~cm}$ indicated by WHO. The studied children have height normal for their age (Table 3). The reason for the observed devia- tions with regard to the average growth is that the larger part of the studied individuals $-71.11 \%(n=90)$ have been observed for a shorter period of time due to their reaching the age of 3 . 
Table 3. Physical development of the studied individuals according to their age at the end of the observation

\begin{tabular}{|l|c|c|c|c|}
\hline \multirow{2}{*}{ Indicators } & \multicolumn{4}{|c|}{ Age } \\
\cline { 2 - 5 } & \multicolumn{4}{|c|}{$2,7-3$ years } \\
\hline Height & $87-90 \mathrm{~cm}$ & $91-94 \mathrm{~cm}$ & $95-98 \mathrm{~cm}$ & $99-102 \mathrm{~cm}$ \\
\hline Relative share & $10 \%$ & $41,11 \%$ & $41,11 \%$ & $7,77 \%$ \\
\hline Weight & $10-12 \mathrm{~kg}$ & $12,1-14 \mathrm{~kg}$ & $14,1-16 \mathrm{~kg}$ & $16,1-19 \mathrm{~kg}$ \\
\hline Relative share & $5,55 \%$ & $41,11 \%$ & $40 \%$ & $13,33 \%$ \\
\hline
\end{tabular}

At the end of the observation, new anthropometric measurements were made to the studied group (as of the time of the last measurements the children are at the age of 2.7 - 3 years). The average height is already $94.2 \mathrm{~cm}$. Again, 4 groups were formed with a $4 \mathrm{~cm}$ interval. The group of the children with height $83-86 \mathrm{~cm}$ does not have representatives so it drops out. The group with height $87-$ $90 \mathrm{~cm}$ remains, with a relative share of $10 \%(\mathrm{n}=90), 91-$ $94 \mathrm{~cm}-41.11 \%(\mathrm{n}=90)$ and two new groups were formed: $95-98 \mathrm{~cm}-41.11 \%(\mathrm{n}=90)$ and $99-102 \mathrm{~cm}-7.77 \%(\mathrm{n}=90)$ (Figure 1).

Fig. 1. Dynamics of the children's height depending on their age

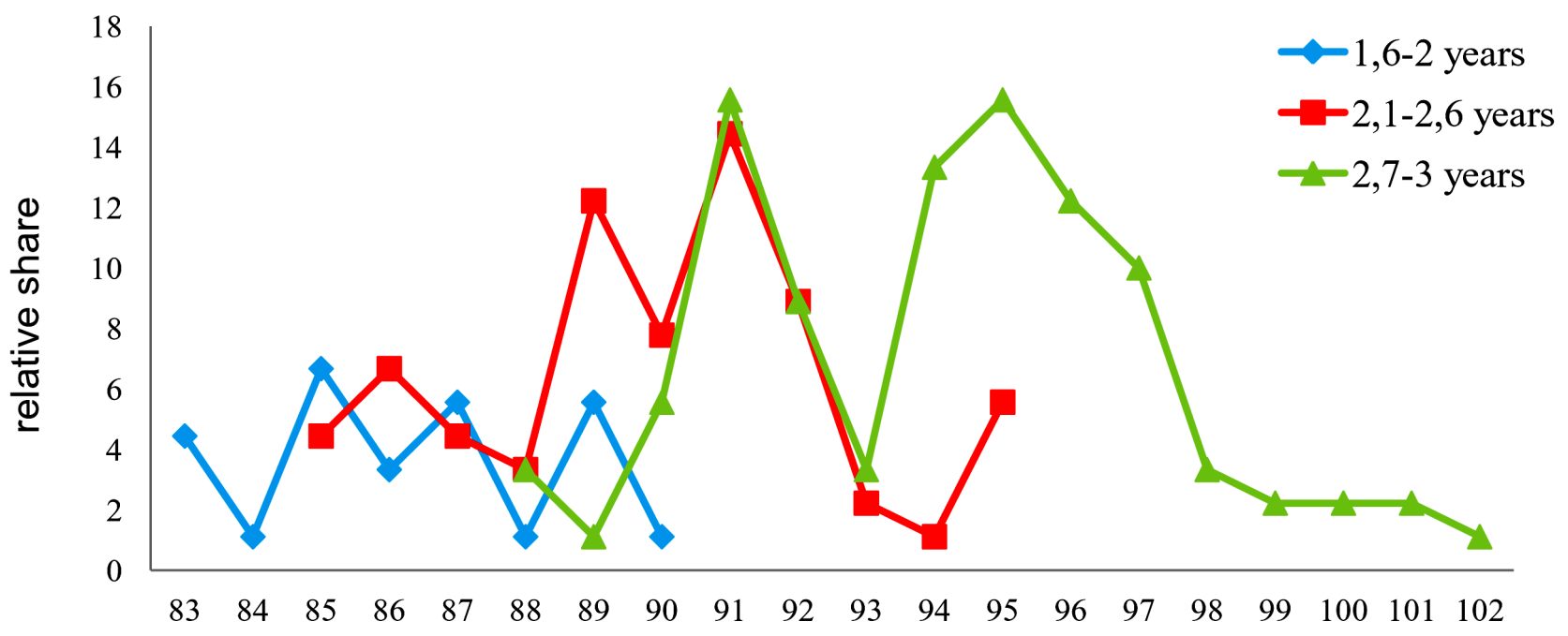

height

\section{DISCUSSION:}

Upon launching of the observation, anthropometric measurements were made in order to track and assess the growth of the studied individuals (note: no measurements of the head and chest have been made, or assessment of the body proportion, because in the s in Bulgaria the nurses only measure height and weight and the other parameters are examined by the general practitioners. The same is valid for the maturity parameters).

Comparing the results with the criteria of WHO [8] it can be said that upon commencement of the observation, the height of all children depending on their age and sex is normal. There are certain deviations above the norm with regard to their body mass (Table 1 and Table 2).

At the end of the study, the average weight has increased by $1,17 \mathrm{~kg}$. According to the standards of WHO, the average increase in the weight between the second and the third year of the children's life is $2.1 \mathrm{~kg}$. With regard to this index, there are no deviations from the norm ei- ther. The children have weight, which is normal for their age and height (Table 3). The observed difference between the standard proposed by WHO and the results of the study is due to the shorter period of observation. The findings of Park AL, Tu K, Ray JG are different: Healthy Canadian infants/toddlers are longer and heavier than the WHO-CGS norms [9].

\section{CONCLUSION:}

1. Positive results have been achieved with regard to the physical development of the children under observation.

2. The results obtained in terms of height and weight completely correspond to the norms for physical development for the relevant age, proposed by the experts of the World Halth Organization.

According to the statement proven by experts of WHO, that the differences in the physical development of children under the age of 5 are more influenced by the 
food, environment and health care than the genetic component and ethnical belonging [6] and taking into consideration the results of our observation, we can conclude that the health care obtained by the children during their stay in the $\mathrm{s}$ are at a satisfactory level.

\section{Conflict of interest:}

There is no additional financing or conflict of interest at the realization if this scientific work. The scientific work has been presented to The Scientific Ethics Committee on February 02, 2015, which gave its opinion with an order of The Rector of Medical University - Pleven No. 344 /20. 02. 2015 .

\section{REFERENCES:}

1. Ordinance No: 26 of 18 November 2008 on the structure and activity of nurseries and children's kitchens and the health requirements towards them. issued by the Ministry of Health, Published SG No: 103 of 2 December 2008. [in Bulgarian] [Internet]

2. Grancharova G, Velkova A, Aleksandrova-Yankulovska S. [Social Medicine] 4th edit. Publishing centre of MU-Pleven. 2015. 320 p. [in Bulgarian]

3. Ivkov B. [Health Promotion Basic Concepts and Definitions.] 2012. [in Bulgarian]

4. Markova S. [Social Medicine and Public Health.] Sofia: Znanie Publishing house. 1996. 255 p. [in Bulgarian]

5. World Health Organization releases new Child Growth Standards. 27 April 2006. [Internet]

6. Grancharova G, AleksandrovaYankulovska S. [Social Medicine.] 5th edit. Publishing centre of MU-Pleven. 2016. 352 p. [in Bulgarian]

7. Births by place of residence, statistical regions, areas and sex in 2018.
National statistical institute of Bulgaria. [Internet]

8. WHO child growth standards: training course on child growth assessment. Interpreting Growth Indicators. WHO. 2008. [Internet]

9. Park AL, Tu K, Ray JG, Canadian Curves Consortium. Differences in growth of Canadian children compared to the WHO 2006 Child Growth Standards. Paediatr Perinat Epidemiol. 2017 Sep;31(5):452-462. [PubMed] [Crossref]

Please cite this article as: Markova G, Petrova G. Analysis of growth indexes in children attending nurseries. $J$ of IMAB. 2019 Jul-Sep;25(3):2706-2709. DOI: https://doi.org/10.5272/jimab.2019253.2706

Received: 27/02/2019; Published online: 26/09/2019

Address for correspondence:

Assoc. Prof. Gergana Petrova, PhD

Department of Nursing Faculty of Public Healthð Medical University - Plovdiv 15A, Vasil Aprilov Blvd., Plovdiv 4002, Bulgaria.

E-mail: gkpg21@yahoo.com 